\title{
Satellite and ground-based observations of a large-scale electron precipitation event.
}

\author{
$\underline{\text { Rory J. Gamble }}{ }^{1}$, Craig J. Rodger ${ }^{1}$, Mark A. Clilverd ${ }^{2}$, Neil R. Thomson ${ }^{1}$, Thomas Ulich ${ }^{3}$, Michel Parrot ${ }^{4}$, Jean- \\ André Sauvaud ${ }^{5}$, Jean-Jacques Berthelier ${ }^{6}$.
}

1. Physics Department, University of Otago, Dunedin, New Zealand. (rgamble@physics.otago.ac.nz, crodger@physics.otago.ac.nz, thomson@physics.otago.ac.nz)

2. British Antarctic Survey (NERC), Cambridge, United Kingdom. (m.clilverd@bas.ac.uk)

3. Sodankylä Geophysical Observatory, University of Oulu, Sodankylä, Finland. (thu@sgo.fi)

4. Laborotoire de Physique et Chimie de l'Environnement et de l'Espace, Orleans, France.

(mparrot@cnrs-orleans.fr)

5. Centre d'Etudes Spatiale des Rayonnements, Toulouse, France. (sauvaud@cesr.fr)

6. Laboratoire Atmosphères, Milieux, Observations Spatiales, IPSL, CNRS, St-Maur-des-Fossés. France. (jeanjacques.berthelier@cetp.ipsl.fr)

\begin{abstract}
Energetic electron precipitation into the atmosphere is determined using subionospheric VLF measurements, DEMETER satellite electron spectra, and modelling techniques for a 24-hour period during the January 2005 geomagnetic storms. Large-scale observations using VLF measurements of multiple subionospheric paths to Sodankylä, Finland, are combined with detailed in situ measurements from the DEMETER satellite to determine the spatial extent, flux, and energy distribution of the precipitation. By providing a better picture of both the intensity and size of the precipitation region, we obtain a more complete picture of the net impact that such an event has on the atmosphere.
\end{abstract}

\section{Background}

In order to describe how geomagnetic storms couple to the upper atmosphere, and hence to atmospheric chemistry and dynamics, measurements of energetic electron precipitation into the atmosphere are required. The process of energetic electron precipitation into the atmosphere produces nitric and hydrogen oxides $\left(\mathrm{NO}_{\mathrm{x}} \& \mathrm{HO}_{\mathrm{x}}\right)$, which are catalysts for the destruction of atmospheric ozone; energetic electron precipitation triggered by geomagnetic storms therefore alters the radiation balance and is a factor in natural climate variability.

Currently, satellite observations are poorly suited to providing measurements of energetic and relativistic electron precipitation. The AARDDVARK network (Antarctic-Arctic Radiation-belt (Dynamic) Deposition - VLF Atmospheric Research Konsortium) provides continuous long-range observations of ionisation levels from $\sim 30-85$ $\mathrm{km}$ altitude by monitoring of subionospheric VLF (very-low frequency) signals, with the goal of increasing the understanding of energy coupling between the Earth's atmosphere, Sun, and Space.

In this study we combine AARDDVARK subionospheric VLF measurements with DEMETER (detection of electromagnetic emissions transmitted from earthquake regions) electron spectra using modelling techniques to study $>100 \mathrm{keV}$ energetic and relativistic electron precipitation into the atmosphere for the 24-hour period beginning 0600UT 19 January, during the 17-21 January 2005 geomagnetic storms. 
The DEMETER satellite provides detailed measurements of drift-loss cone electrons during this event, which are used to provide an indication of the precipitating (bounce-loss cone) electron energy spectra. Perturbations in subionospheric VLF amplitudes caused by the electron precipitation event are measured on two paths using the AARDDVARK network. Modelling of VLF propagation in response to the precipitation region reveals its $L$ range and flux intensity. 